\title{
A Study on the Success Factors of Bio Cluster : Focused on the Development of Integrated Framework*
}

\author{
Gyu-Bae KIM ${ }^{1}$, Kyung-Keun KIM ${ }^{2}$, Seung-Hwan CHUNG ${ }^{3}$ \\ 1 First Author Professor, Department of Business Administration, Daejeon University, Daejeon, Korea. \\ E-mail: gbkim@dju.ac.kr \\ 2 co-Author Manager, Daejeon \& Chungnam Branch Office, Bank of Korea, Daejeon, Korea. \\ E-mail:kkk3k94@bok.or.kr \\ 3 co-Author Manager, Chungbuk Branch Office, Bank of Korea, Chungbuk, Korea. \\ E-mail: sh.chung@bok.or.kr
}

Received: 23 May 2020. Revised: 13 June 2020. Accepted: 17 June 2020

\begin{abstract}
Purpose - This study incorporated the success factors of bio cluster and provided the ways to utilize them for managing the performance of bio cluster. The aim of this study was to present an integrated framework for the success factors of the bio cluster by combining the literature and case studies, and to measure and manage the performance of the bio cluster.

Research design, data, and methodology - This study combined the literature review with the case study. We reviewed the literature on the success factors of the bio cluster presented by existing studies. We studied some cases of how these factors are actually applied in the bio cluster also. We integrated the success factors of bio cluster based on both the literature review and the case study.

Results - The success factors of the bio cluster presented in this study as an integrated framework were defined as six factors: knowledge base and expertise, industrial infrastructure, funding and investment, government support, start-up activities and innovation activities. These success factors can be measured and managed by some performance indicators of each factor.

Conclusions - Through this study, we can identify the integrated success factors of the bio cluster and understand how these factors work in bio cluster. In addition, this integrated framework of success factors will be effectively utilized to measure and manage the performance of the bio cluster.
\end{abstract}

Keywords: Bio cluster, Success Factors, Integrated Framework

JEL Classification Code: L65, M10.

\footnotetext{
* This pager is part and summary of the report of joint research with Bank of Korea and the research was supported by Bank of Korea. This paper is the personal opinion of the authors.

(c) Copyright: The Author(s)

This is an Open Access article distributed under the terms of the Creative Commons Attribution Non-Commercial License (http://Creativecommons.org/licenses/by-nc/4.0/) which permits unrestricted noncommercial use, distribution, and reproduction in any medium, provided the original work is properly cited.
} 


\section{Introduction}

Bio industry is one of the three main industries selected by the government and is highly promising in terms of growth potential and ripple effects. Currently, major advanced countries and leading bio companies in those countries are leading the global market, but it is expected to be a great opportunity for Korean industries and companies because of the big size of the market involved in bio industry and the possibility of industrial development. The bio industry has a very long development period for products and requires vast amounts of money in the process, and has a very high failure rate for development. Although it is such a risky industry, there is also a characteristic that the rewards that come when development leads to success occur are very large over a long period of time. It is remarkable that the government announced its "Bio-Health Industry Innovation Strategy" in May 2019 and is seeking to develop the bio industry of Korea. The research for the development of the domestic bio industry has continued in recent years also (Choi et al., 2019; Kang et al., 2019; Park \& Jeong, 2019).

There are some characteristics of the bio industry. Pisano (2006) presents three characteristics of the bio industry. First, the uncertainty is large and persistent because of the biotechnology characteristics, second, the knowledge needed for research and development is very heterogeneous and diverse, and third, learning should be cumulative because the necessary skills and knowledge develop rapidly. It also said that these three characteristics require risk management, integration and cumulative learning to be considered in the business. The characteristics and necessary tasks of the bio industry require high levels of cooperation among the players involved in the bio industry. This is because subjects in the bio industry can reduce $R \& D$ risks, integrate diverse knowledge, and reflect rapidly changing technologies and knowledge by attempting to link and integrate based on each other's expertise. Therefore, the importance of inter-subsidiary cooperation in the bio industry, as mentioned continuously in this study, stems from the nature of the bio industry. Shortly, the bio industry has the characteristic that knowledge and skills in a wide range of fields produce innovative results through interaction and integration. Therefore, it is necessary for specialized personnel, equipment and information related to the bio industry to be aggregated and utilized in specific areas, and it is important to build and develop a bio cluster to develop bio industry. This is because bio cluster allows organizations and companies related to the bio industry to geographically close and achieve sharing, cooperation and innovation. Indeed, countries with advanced bio-industries have representative bio clusters in their countries, and renowned global bio companies are one of the innovators in these bio clusters.

Bio industry with a strong technology-intensive nature tends to converge in certain areas (Coen et al., 2004) because it requires aggregation of professionals, equipment, technology, knowledge and information to satisfy the technology-intensive characteristics. In addition, technology-intensive industries such as bio industry are more important to interact with and interact with cluster players, and to learn and create ideas through them, and bio cluster is useful in that it is also regional integration to facilitate a close network of innovators. Korea also has bioindustrial complexes that can be named bio clusters nationwide, and representative bio clusters exist in Gyeonggi-do, Incheon-si, Gangwon-do, Chungcheongbuk-do, Daejeon-si and Daegu-si. It is very important to develop and manage these domestic bio clusters in order for the domestic bio industry to develop and for the global status of local bio companies in Korea to rise in the global market. Developing and managing bio clusters well will require understanding the success factors of the bio cluster and managing the bio cluster based on these success factors. Indeed, it is said that it is important to maintain and coordinate clusters to innovate and increase competitiveness in the bio industry (Europe Innova, 2008).

Existing studies have addressed both the success factors of a typical industrial cluster and those of a bio cluster specific to the bio industry (DTI, 1999; Bok et al., 2002; Lee \& Kim, 2003; KHIDI, 2017). Many studies also have been conducted on the cases of bio clusters around the world to identify and understand the success factors of bio cluster (Lee \& Kim, 2003; Jeong et al., 2011; Kim, 2014; Park, 2017). These existing studies conducted literature review or case study related to the success factor of bio cluster. This study is meaningful in that it used research methodology that integrates both literature review and case studies together to identify and develop the framework for success of bio cluster. This study intended to present an integrated framework that could be used both to understand the success factors of a bio cluster and to operate and manage a bio cluster. This study examined not only the integrated success factors of bio cluster but also the items to analyze and evaluate individual success factors to perform a comparative analysis relative to other bio clusters. Domestic bio clusters will be able to use the results of this study both to identify strengths and weaknesses from the perspective of cluster success factors and to drive improvement tasks.

This study consists largely of three parts. Following this introduction, the literature review section will review and organize the existing literature on the outline of the bio industry, the concepts and success factors of the bio cluster. In the following sections, we will analyze the cases of major bio clusters around the world, focusing on the 
success factors of the bio cluster we've identified earlier. Based on the results of the existing literature review and case analysis, the next section presents the success factors of the bio cluster as an integrated framework and discusses how to utilize these frameworks for measuring and managing performance of the bio cluster. Finally, the conclusion section describes the summary and implications of this study including its limitations and further research.

\section{Literature Review}

\subsection{Bio industry Overview}

Bio industry can be called biotechnology industry or biotech industry. It can be defined as an industry that uses the functions and information of living things to produce useful materials and services that mankind needs based on biotechnology. Bio industry can vary in scope and detailed types of industries in that it means industries that generate added value by applying biotechnology in various industrial sectors such as conventional medicine, chemicals, food, environment, electronics and agriculture. Indeed, the concept and scope of the bio industry, and international standards for detailed classification systems within the industry, do not yet exist. In the U.S. and Europe, they also use different ranges and classification systems, and global market research institutes related to the bio industry use different standards.

In Korea, reflecting the results of the research by the Ministry of Trade, Industry and Energy, the National Institute of Technology and Standards established the national standard in 2008, which classified the bio industry into eight categories, and in 2016, it was revised and used as the first. According to the report, the scope of the bio industry has been clarified as "companies that use biotechnology in the R\&D, manufacturing, production and service stages," and the detailed industrial classification consists of eight sections and 51 divisions. Eight detailed industries are divided into bio-medicine, bio-chemical and energy, bio-food, bio-environment, bio-medical devices, bioequipment and devices, bio resources and bio-service industries.

There is a bio-health industry, a term widely used with the term bio industry. The government's recent announcement is also named "Bio Health Industry Innovation Strategy," and academic and working-level circles are using a mix of bio-health and bio industry. In general, the bio-health industry is used as a broader concept, including the bio industry, and it can be understood that within the bio-health industry includes the bio industry, pharmaceutical industry, and medical device industry.

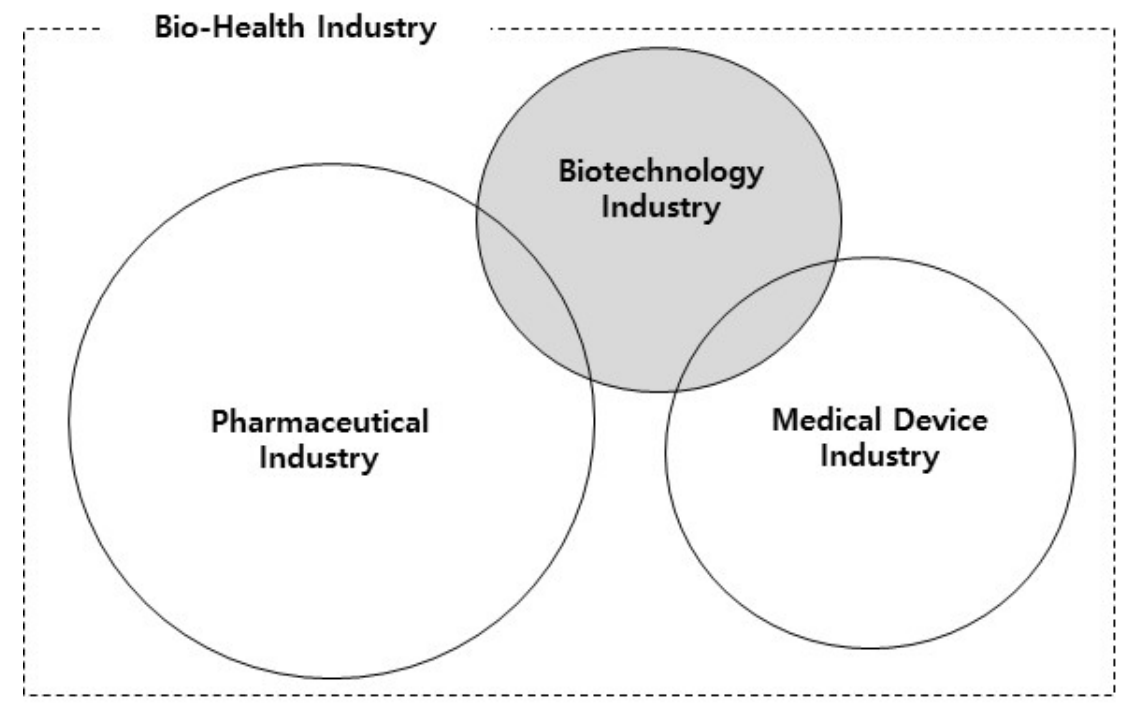

Source: Korea Biotechnology Industry Organization

Figure 1: Bio-Health Industry and Bio Industry

Figure 1 illustrates the relationships between some terms about bio industry. Meanwhile, global market research in the bio-health industry and bio industry also covers both the healthcare industry and the bio industry of 
consultation, with 'Frost \& Sullivan' regularly publishing health-care industry reports and 'Marketline' publishing bio industry reports. As mentioned earlier, there is no international standard yet for the concept and scope of the bio industry, so it will not be possible to exactly match the terms used domestically with those used abroad. In general, the term bio-health industry used in Korea and the term "Frost \& Sullivan" by global market research institutes can be understood as a concept of light, and the term "bio industry" in Korea and "Marketline" by global market research institutes can be understood as a concept of consultation. The bio industry used in this study is used as a concept of consultation.

\subsection{Factors for Success of Bio cluster}

\subsubsection{Bio Cluster Overview}

It has been emphasized that the term cluster has long been used in the theory of industrial location in economics, resulting in mass production and economic effects in industrial complexes aggregated within the same region. Michael Porter describes the concept of a cluster by incorporating it into the theory of competition, which can be defined as a group of geographically adjacent enterprises or institutions connected through similarity and completeness (Porter, 2000).

Governments and major institutions have conducted research with interest in the positive impact of clusters on industrial development, and in the mid-1990s, the OECD formed a cluster research group (cluster focus group) and analyzed cluster cases in OECD countries. The OECD defines the concept of a cluster as "a network between companies with strong independence (universities, research institutes, knowledge-providing companies), organizations (knowledge-intensive business services, consultants, and customers) linked to the production value chain that creates value-added." Through industrial clusters, economies of scale and economies of scope can be achieved, and since the 1990s, it has been used as a means of economic growth and industrial development. The concept of a cluster can be viewed as a common element in terms of linkage between the entities and agencies involved, geographic focus, and the same or similar area of industry, and can have an advantage in terms of innovation activities through exchanges and interactions among members participating in the cluster (Coen et al., 2004).

If the concept of an industry cluster applies to the bio industry, it can be named bio cluster which could be called biotech cluster or biotechnology cluster. Indeed, innovation cluster models based on science and technology, such as bio clusters, are used as tools for economic development and advanced industrial development at many national or regional levels around the world.

\subsubsection{Success Factors of Bio Cluster}

Many researches have addressed both the success factors of a typical industrial cluster and those of a bio cluster specific to the bio industry. We will review existing studies focusing on the success factors of the bio cluster. DTI (1999) presents 10 factors related to success of the bio cluster. The ten success factors are strong science base, entrepreneurial culture, growing company base, ability to attract key staff, premises and infrastructure, availability of finance, business support services and large companies, skilled workforce, effective networks, and supportive policy environment. Table 1 summarizes the main contents.

The American Bio Industry Organization (BIO, 2002) presented through its policy research large public and private research institutes, universities, pharmaceutical companies, highly educated skilled workers, quality of life, reasonable environmental regulations, as well as stable power supply corresponding to local living infrastructure, safe drinking water sources and good sewage facilities. Practically, in 2001, Boston Consulting Group (BCG) used excellent research institutes and support agencies, technology and know-how transfers for industrialization of science and technology, venture and research support for venture capital, excellent research and support personnel, laboratory/production facilities/office/traffic infrastructure, and policy environment goodwill in its assessment of the maturity of six leading bio clusters around the world.

There are also studies that emphasize the most key success factors rather than presenting various and broad factors for bio cluster success, with OECD (2001) saying that high-tech industry clusters focus on venture firms or small- and medium-sized enterprises for success, while Powell et al. (2002) singled out science and technologybased and capital elements as the most important factors for the growth of the bio industry in regional clusters. European Innova (2008) emphasized the participation of highly capable universities, research institutes, large enterprises, and the existence of bio-technology companies for the success of the bio cluster, while Ketels (2003) 
emphasized strong leadership at the regional level encompassing universities, businesses and governments, as well as partnerships between the public and private sectors in the cluster. Bio cluster has universities and research institutes, and active public research and development between them and businesses (Murray, 2004), because linking and cooperating activities are critical to success in that the bio industry is a high-tech industry with high technological instability (Casper, 2007).

Table 1: Factors that encourage cluster development

\begin{tabular}{|c|c|}
\hline Factors & Items \\
\hline Strong science base & $\begin{array}{l}\text { Leading research organizations: University departments, } \\
\text { hospitals/medical schools and charities } \\
\text { - Critical mass of researchers } \\
\text {. World leading scientist(s) }\end{array}$ \\
\hline Entrepreneurial culture & $\begin{array}{l}\text { - Variable Commercial awareness and entrepreneurship in Universities } \\
\text { and research institutes } \\
\text { - Role models and recognition of entrepreneurs } \\
\text { - Second generation entrepreneurs }\end{array}$ \\
\hline Growing company base & $\begin{array}{l}\text { - Thriving spin-out and start-up companies } \\
\text { - More mature 'role model' companies }\end{array}$ \\
\hline Ability to attract key staff & $\begin{array}{l}\text { - Critical mass of employment opportunities } \\
\cdot \text { Image/Reputation as biotechnology cluster } \\
\text { - Attractive place to live }\end{array}$ \\
\hline Premises and infrastructure & $\begin{array}{l}\text { Incubators available close to research organizations } \\
\text { - Premises with wet labs and flexible leasing arrangements } \\
\text {. Space to expand } \\
\text { - Good transport links: Motorways, Rail, International airport }\end{array}$ \\
\hline Availability of finance & $\begin{array}{l}\text { Venture capitalists } \\
\text {. Business angels }\end{array}$ \\
\hline $\begin{array}{l}\text { Business support services and large } \\
\text { companies }\end{array}$ & $\begin{array}{l}\text { - Specialist business, legal, patent, recruitment, property advisors } \\
\text { - Large companies in related sectors (healthcare, chemical, agrifood) }\end{array}$ \\
\hline Skilled workforce & $\begin{array}{l}\text { - Skilled workforce } \\
\text {. Training courses at all levels } \\
\end{array}$ \\
\hline Effective networks & $\begin{array}{l}\text { - Shared aspiration to bel a cluster } \\
\text { - } \text { Regional trade associations } \\
\text { - Shared equipment and infrastructure } \\
\text { - } \text { Frequent collaborations }\end{array}$ \\
\hline Supportive policy environment & $\begin{array}{l}\text { - National and sectional innovation support policies } \\
\text { - Proportionate fiscal and regulatory framework } \\
\text { - Support from RDAs and other economic development agencies } \\
\text { - Sympathetic planning authorities }\end{array}$ \\
\hline
\end{tabular}

Source: DTI (1999)

According to domestic studies, Bok et al. (2002) presented practical network, abundant resources, harmonization of private-government roles, leadership of leaders, enhanced systems of technological innovation, and specialized service, related industries as success factors for bio clusters while discussing strategies for the development of bio cluster, Lee and Kim (2003) explored common success factors of bio clusters such as a strong research base, 
excellent professionals, abundant capital, well-developed infrastructure, a favorable legal/tax system and active networking through analysis of bio cluster cases in the U.S. and U.K. Han (2003) analyzed U.S. bio cluster policies, saying that even with a good research base and infrastructure, a lack of venture capital or entrepreneurship could lead to a failure of a bio cluster, while other necessary factors also pose obstacles to success if a lack of capabilities within the cluster. KHIDI (Korea Health Industry Development Institute) (2012) emphasized competition and cooperation among innovation players in the cluster, incentives for innovation players, universal feasibility of technology evaluation, and entrepreneurship as conditions for the formation and revitalization of bio clusters.

\section{Case Study}

\subsection{Overview of Bio Cluster Cases}

There are many studies conducted on the cases of bio clusters around the world. A study by Lee and Kim (2003) dealt with bio cluster cases in the U.S. and Britain, while a study by Jeong et al. (2011) analyzed cases in the U.S., Britain and Japan. Kim (2011) compared and analyzed the cases of the United States, Britain, Singapore and Korea, while Kim (2014) deals with the cases of East Asian countries such as Japan, Singapore and Korea. Kim (2016) analyzed and suggested bio cluster cases in the United States, Singapore, Ireland and China, while Park (2017) deals with cases in the United States, Singapore and Ireland. As such, bio clusters around the world are distributed in many countries, and in some cases they have several famous clusters within a country. In addition, looking at previous studies of bio cluster cases, the characteristics and types of individual bio clusters vary widely. There are also studies that analyze bio cluster cases with various characteristics from a certain point of view (Eun, 2015), which analyzed British cases from a dynamic evolutionary perspective of clusters (Lee and Lee, 2015), and studies that analyzed U.S. cases from a growth strategy perspective (Eun, 2016) compared with domestic ones. The main points of this case analysis are based on the above-mentioned case studies.

Bio clusters appearing in various forms around the world can be categorized according to their purpose. Coe et al. (2007) had classified seven types according to the cluster industry, internal mobility, and geographical size, while Lee and Lee (2008) said it was difficult to clearly distinguish industrial cluster types in reality. Bio clusters in North America and Europe are divided into self-sustaining, university-led, and government-led (Korea Health Industry Promotion Agency, 2010) and Kim (2014) study examines the characteristics of government-led clusters by dividing them into government-led and private sector led ones.

In this case analysis, we would like to distinguish key bio cluster cases around the world from government-led to private sector led. All bio clusters include government support and private voluntary efforts. Therefore, the distinction between cluster types is relative, with government-led clusters being a form of government-led involvement in planning and implementing the necessary tasks for the cluster's creation and growth process, and private section-led clusters being a form of large characterization of growth and synergies through voluntary participation by innovators in the cluster. Table 2 shows two kinds of cases that this study analyzed.

Table 2: Bio Cluster Cases

\begin{tabular}{|l|l|}
\hline \multicolumn{1}{|c|}{ Private Sector led Bio Clusters } & \multicolumn{1}{c|}{ Government led Bio Clusters } \\
\hline$\cdot$ San Diego Cluster, USA & $\cdot$ Kobe Cluster, Japan \\
$\cdot \begin{array}{l}\text { Cambridge Cluster, UK } \\
\text { Boston Cluster, USA }\end{array}$ & $\cdot$ One-North Cluster, Singapore \\
\hline
\end{tabular}

\subsection{Private Sector led Bio Clusters}

\subsubsection{San Diego Cluster, USA}

In San Diego, the U.S., tourism and defense industries were originally the center of the local economy. But it was reborn as a bio industry with the establishment of the Salk Institute for Biological Studies in 1955, the Scripps Research Institute in 1960, the University of California San Diego in 1964, and the region's first biotech company Hybritech in 1978. 
The San Diego Cluster is home to the world's leading basic science institutes, the Salk Institute and the Scripps Research Institute, focusing on UCSD, which is strong in bio and medical research. Through the aggregation of universities and related research institutes, it was easy to connect and cooperate with each other and was used to develop new drugs and medical devices. In the case of new drug development, the company focuses on developing candidate materials and then commercializes them through the use of CRO (contract research organization) or partnerships with large pharmaceutical companies. In the case of medical devices, the San Diego Cluster is the most famous area, and since hybritech succeeded in launching the first prostate cancer diagnostic, it has continued to be a major area in the region.

Within the San Diego Cluster, UCSD and research institutes (Salk Institute for Biological Studies, Scripps Research Institute, Burnham Research Institute, etc.) play key roles as R\&D players, but 1,100 companies in the region and 80 independent research institutes and research institutes belonging to universities are also conducting industry-academic research. In the cluster area, UCSD's medical center, Sharp Memorial Hospital and nine other hospitals are performing clinical trials and other roles. In addition, investment companies such as angel investors, venture capital, and banks perform their funding functions within the ecosystem. Meanwhile, there is a non-profit organization called CONNECT within the San Diego Cluster, which is established for the purpose of industryacademic cooperation and focuses on the formation of relations between universities and businesses, and operates in a flexible structure that does not intervene even when cooperation is made. The support of this cooperative process facilitates the exchange of R\&D and new technology information, information on management general and information on investment among the cooperative entities, and based on this, joint start-ups, investor security and human and material exchanges will be activated. In short, CONNECT further strengthened the industrial ecosystem of the San Diego bio cluster in that it provided a mechanism to link people, technology, and capital, as a result, by activating the linkage and cooperation among the innovators in the cluster.

\subsubsection{Cambridge Cluster, UK}

The Cambridge Cluster in UK is the most advanced of the bio clusters in many European countries. In the 1970s, Trinity College in Cambridge led the creation of an industrial complex, bringing together many high-tech companies in the region, especially near University of Cambridge, the region's leading university and UK's. In the process, Cambridge Science Park was created to provide support to companies, and a number of companies, including those that moved into the area, were integrated. High-tech companies that began to converge in the 1970s grew rapidly through the 1980s and 1990s, increasing to nearly 1,000 in 1999.

The innovation players of the Cambridge cluster played a key role in University of Cambridge and Addenbrooke's Hospital. University of Cambridge had a leading presence in many areas, so related research institutes and companies could gather around it. In addition, many of the research and start-up staff in the cluster area are from University of Cambridge. In order to utilize University of Cambridge with such outstanding capabilities, many companies and research institutes have gone through the process of creating a self-sustaining cluster. The growing number of start-up companies, including those dispersed at University of Cambridge and Addenbrooke's Hospital, has led to the creation of many business support facilities and service providers to support them. In addition, global pharmaceutical companies like Merck and biotech companies like Amgen are clustered in clusters with bio venture firms.

Cambridge Cluster has a strong scientific academic foundation centered around University of Cambridge and numerous research institutes established around it, close industry-academic cooperation between high-tech companies in the region has been achieved, and institutions supporting networking and start-up child care in the region have played a good role. In particular, the CTG (Cambridge Technopole Group) is an informal network of local-run corporate support agencies, which is linked by sector to universities, network-specialized institutions, investment and financial institutions, legal and accounting organizations, etc. that technology companies need.

\subsubsection{Boston Cluster, USA}

The Boston area of the United States has grown with the progress of the United States from an economic point of view In the 1960s and 1980s, the industry was centered on electronics, telecommunications, computers, aerospace, and national defense, and after the mid-1990s, it developed into an industrial structure based on advanced science and technology such as computer S/W, IT services, pharmaceuticals, and medical care. Since then, it has evolved from S/W and IT service centers to BT (Bio Technology)-centric industrial structures, growing into a global bio cluster. 
The Boston Cluster in the U.S. is the world's best cluster, where local innovators have been growing on their own, working closely together. Innovative ventures have emerged around universities and research institutes such as Harvard University and MIT in the region, and global pharmaceutical companies that need these innovative ventures have gathered and grown here.

Innovators in the cluster have played their respective roles, collaborated and completed the local bio industry ecosystem. Universities and research institutes provide the foundation for original technology, talent and venture start-ups, hospitals are responsible for clinical trials, and pharmaceutical companies take the initiative in commercializing the technology. Based on technologies developed around universities, research institutes and hospitals, researchers will carry out venture startups themselves, which will make it easier to link the commercialization of original technologies. Based on its rich investment experience, professional venture capital in the region plays a role as a venture incubator by providing advice and funding needed for venture firms to grow.

Inside the Boston cluster are large global pharmaceutical companies, innovative bio venture firms and top 5 hospitals in the U.S., which are considered one of the world's leading bio clusters as well as the U.S., where industry, academia and research are linked. The Boston Cluster has grown on its own, but government support has continued in the process. The Massachusetts government has continued to invest in the development of the bio industry, and Boston is the city where the NIH (National Institutes of Health) funds are most supported. Therefore, governmentled bio clusters should not be understood as having a lot of government support, while private sector led bio clusters lack government support. It should be understood that government initiative is to lead the formation and budget utilization of industrial ecosystems, while private initiative is to support the government's support for what is needed for self-sustaining ecological activities.

\subsection{Government led bio cluster}

\subsubsection{Kobe Cluster, Japan}

After the 1995 Kobe earthquake, Japan's Kobe city planned to create a medical industrial complex with the aim of reviving the local economy, and carried out a second-phase development on an artificial island off Kobe called Port Island. The city of Kobe has begun to attract various institutions related to the medical industry within the region with state support. In order to attract businesses, the government and Hyogo Prefecture provided various subsidies and tax reduction efforts, and the Kobe Advanced Medical Promotion Foundation was established to take charge of the implementation of the establishment of a medical industry city.

Within the Kobe cluster, large companies, small and medium-sized enterprises, and bench companies are all distributed, and the types of companies vary, including research and development, manufacturing and service, and sales expertise. Five universities, including Kobe Gakuin University and Hyogo College of Medicine are located in the cluster, and many research centers of the RIKEN which was set up through government projects are working on research and development with hundreds of employees.

The Kobe FBRI (Foundation for Biomedical Research Innovation) has IBRI (Institute of Biomedical Research and Innovation, TRI (Translational Research Center for Medical Innovation), RDC (Research and Development Center for Cell Therapy), and CCD (Center for Cluster Development and Coordination) under its organization. IBRI Creates new medical seeds with a focus on "immunology R\&D", "R\&D, for the aging" and "regenerative medicine R\&D”. TRI Supports for the development of new medical seeds in Japan and overseas, with a focus on the research and development seeds of FBRI. CCD provides Providing one-stop services to respond to a wide range of support needs in a centralized manner, from the identification of seeds to intellectual property, pharmaceutical consultations, and sales channel development. There is also BMA (Business Support Center for Biomedical Research Activities, which supports the commercialization of technologies by bio-venture companies and medical institutions. It is equipped with laboratories, production facilities and laboratories and provides rental services to businesses and research institutes. Japan can provide a positive foundation for the growth of the Kobe cluster, given that its pharmaceutical companies account for a high share of the global market and that research in the bio sector is also high. In addition, the fact that the Japanese government and Kobe City have made efforts to develop the medical industry simultaneously also played a positive role in the cluster's development of the cluster.

\subsubsection{One-North Cluster, Singapore}

The Singapore government began to select and intensively foster the bio industry as a new growth engine industry as the electronic industry, which was the driving force of economic development until the 1990s, became 
no longer able to play its role. Since 2000, it has been aiming for a bio hub in Asia and has implemented a government-led policy of fostering industries with massive capital injections.

Singapore's One-north Cluster consists of Biopolis, a research and development hub, and a production-oriented Tuas Medical Park. Biopolis is home to global pharmaceutical companies and Singapore's state-run think tanks, and pharmaceutical companies and research institutes have been conducting joint research together. Tuas Medical Park is used to manufacture and produce bio-medicine, and pharmaceutical companies equivalent to the Global TOP 10 have established and operated production bases here.

Through tax incentives and joint infrastructure provision, the Singapore Bio Cluster attracted global pharmaceutical companies and related research institutes, and actively operated a manpower training program to supply outstanding talent in local industries. First, in terms of tax incentives, the corporate tax rate in Singapore is at around 17 percent, lower than in other competitors, and it has granted a full exemption of corporate taxes for up to 15 years for technology-leading companies that meet certain conditions. When it comes to joint infrastructure, many facilities and equipment which are essential to pharmaceutical and biotechnological research have been provided for joint use. To foster professional manpower, the National University of Singapore (NUS) and Duke University of the United States jointly established and operated Duke-NUS Graduate School of Medicine. In addition, a long-term overseas study program supported by the government provided expenses for science majors to study abroad for eight to nine years, and when they finished studying abroad, they were required to return to Biopolis for five to six years. Singapore's One-North Cluster is an example focused on the synergy of industrial infrastructure and professional talents with full support from the government.

\subsubsection{Dublin \& Cork Cluster, Ireland}

Ireland's bio cluster has begun as a production hub for global pharmaceutical companies and is gradually achieving results in attracting R\&D centers and headquarters. Ireland is the No. 1 production hub for global pharmaceutical companies in Europe, with most global pharmaceutical companies placing their production plants or headquarters in Ireland. Dublin mainly has the headquarters of a global pharmaceutical company and performs sales and support functions, while Cork mainly has manufacturing facilities and is in charge of production functions.

Ireland has been developing the cluster by attracting global pharmaceutical companies through unconventional tax policies and supplying outstanding human resources through active training of human resources. First of all, in terms of tax policy, global pharmaceutical companies have been attracted by offering the world's lowest corporate tax rate of $12.5 \%$, the reduction of corporate tax rate on patent income $(6.25 \%)$, and the tax deduction for R\&D expenses (up to $37.5 \%$ ). In the case of global pharmaceutical companies with high operating profit ratios, Ireland's tax policy worked very successfully in that the most important factors to consider in selecting overseas hubs were various tax incentives such as corporate tax and tax deductions. In addition, the National Institute for Bioprocessing Research and Training (NIBRT), which was established by the government with an investment of about 60 million euros to provide necessary human resources to the production facilities of Ireland's attracted global pharmaceutical companies, is conducting professional training for visitors not only from Ireland but also from around the world.

Ireland has attracted about 4 trillion won in new investments from 2011 to 2015, although it suffered economic difficulties during the 2008 financial crisis. As a result, nine of the top 10 global pharmaceutical companies were located in Ireland as of 2014, making it the seventh largest exporter of pharmaceuticals in the world.

\section{Integrated Framework of Success Factors}

\subsection{Integrated Success Factors of Bio cluster}

This study examined existing studies of bio cluster success factors, and it analyzed representative cluster cases based on those success factors. This study wanted to examine common success factors applicable to the bio industry in Korea through the review of existing studies and the analysis of examples.

Lee and Kim (2003) explored common success factors of bio clusters and analyzed the results of six domestic and foreign studies on the success factors of bio clusters, showing the success factors commonly presented in individual studies among the 11 success factors covered by the six studies. The 11 success factors presented by the six studies on bio clusters consist of strong research bases, excellent professionals, abundant capital, innovative

corporate culture, well-developed infrastructure, favorable legal/tax systems, aggregated industry, active networking, large market (investigation), leadership, legal and consulting of leaders (business/management). Success factors 
commonly presented by more than three of the six studies were found to be six factors: a strong research base, excellent professionals, abundant capital, well-developed infrastructure, a favorable legal/tax system and active networking.

On the other hand, although no common success factors have been derived from the study, many studies have dealt with start-up activities such as entrepreneurship and venture business revitalization as success factors for the bio cluster. DIT (1999) deals with entrepreneurship culture and revitalization of start-ups as two of the 10 success factors, while OECD (2001) said venture companies or small and medium-sized enterprises are important for a cluster of high-tech industries to succeed, and Han (2003) said that even if one bio cluster has other success factors, it could fail without entrepreneurship or venture capital. Therefore, how active the start-up activities of the bio cluster are also seen as important common success factors.

In this study, the six common success factors (strong research base, excellent professionals, abundant capital, well-developed infrastructure, favorable legal/tax system, active networking) presented by Lee and Kim (2003) and other successful factors were integrated into the six success factors to use in analyzing the situation of this study. Strong research bases and excellent professionals were integrated into one factor, 'knowledge base and professional workforce', and abundant capital and well-developed infrastructure were defined as 'fund and investment' and 'industrial infrastructure' factors, respectively, and active start-up activities were named 'start-up activities'. Finally, the favorable legal/tax system expanded the concept due to the factor 'government support', and active networking activities expanded to 'innovation activities' including R\&D activities of existing companies.

The new integration and expansion of the common success factors of the bio cluster in this study was carried out by reference to other existing studies and in-depth interview results on the site. Finally, the common success factors of the bio cluster presented as an integrated framework in this study were defined as six factors: knowledge base and expertise, industrial infrastructure, funding and investment, government support, start-up activities and innovation activities. Table 3 shows the process of integrating factors for success of bio clusters.

Table 3: Integrated Success Factors of Bio Cluster

\begin{tabular}{|c|c|c|c|c|}
\hline $\begin{array}{c}\text { Main Success Factors of } \\
\text { Existing Studies }\end{array}$ & & $\begin{array}{c}\text { Another Factors of } \\
\text { Other studies }\end{array}$ & & $\begin{array}{c}\text { Integrated Success Factors of } \\
\text { Bio Cluster }\end{array}$ \\
\hline $\begin{array}{l}\cdot \text { Strong research base } \\
\cdot \text { Excellent professionals } \\
\cdot \text { Abound capital } \\
\cdot \text { Well-developed infrastructure } \\
\cdot \text { Favorable legal/tax system } \\
\cdot \text { Active networking } \\
\cdot \text { Active start-up activities }\end{array}$ & + & $\begin{array}{l}\text { Entrepreneurship culture } \\
\text { and Revitalization of start- } \\
\text { ups } \\
\text { - Venture companies and } \\
\text { Small and medium-sized } \\
\text { enterprises } \\
\text { - Entrepreneurship or venture } \\
\text { capital }\end{array}$ & $\rightarrow$ & $\begin{array}{l}\text { - Knowledge base and } \\
\text { expertise } \\
\text { - Industrial infrastructure } \\
\text { - Funding and investment } \\
\text { - Government support } \\
\text { - Start-up activities } \\
\text { - Innovation activities }\end{array}$ \\
\hline
\end{tabular}

There could be the process in which six factors act on the success of the bio cluster is as follows. First, the local knowledge base, professional manpower and infrastructure elements of the bio industry become the basis conditions for new bio companies to be created and grow early. On top of that, funding and investment are made to support companies' start-ups and childcare, and active government support can promote the growth of the bio industry in the region. Finally, in order for the bio industry ecosystem in the region to have a continuous virtuous cycle, new companies will have to continue to start up and enter the ecosystem, and existing ecosystem members will have to make efforts to create innovative values through sharing and cooperating with each other as well as continuous research and development activities.

On the other hand, six common success factors defined by an integrated framework could be used to analyze the status of a particular bio cluster or to perform a comparative analysis relative to other bio clusters. For example, knowledge and manpower factors, one of the success factors for a bio cluster, could be analyzed using performance indicators, such as the number of patents and the number of Ph.D. personnel, while government-backed factors could be evaluated by region through the size or characteristics of organizations supporting the bio industry. Here we discuss how to assess integrated success factors for bio clusters. 


\subsection{Utilization of Integrated Framework for Bio Cluster Management}

Due to the nature of the bio industry, which is a high-tech industry and a scientific industry, knowledge base and professional manpower are necessary conditions for industrial development. In this study, the knowledge base can be examined by the number of patent holders in the region, the number of SCI papers, and the number of patents, and professional personnel can be identified by the number of bio industry workers in the region, the number of researchers, and the number of Ph.D. personnel.

Many of the bio industry infrastructure factors mentioned in previous studies related to bio cluster include sites, facilities, and equipment. And these infrastructures vary in detail depending on small and medium enterprises and large enterprises, R\&D functions and production functions. Thus, bio industry infrastructure factors will be identified from the infrastructure perspective for supporting equipment and occupancy facilities in the bio cluster region and for $\mathrm{R} \& \mathrm{D}$ and production in the bio cluster region.

Bio companies, which were founded with the help of family and friends, grow by utilizing government subsidies, angel investment and venture capital funds before gaining stable financing and investment. Therefore, funds and investment factors can be identified through the use of R\&D funds by regional governments and venture investment conditions by region.

Unlike European countries and the United States, which are advanced countries in the bio industry, the size and capacity of the domestic bio industry is still insufficient. Therefore, the government's policy support is critical if it wants to nurture the bio-health industry as one of the top three industries in consideration of the potential growth potential of the global bio industry and the potential of the domestic bio industry. The government's support policy is also one of the many bio cluster success factors mentioned in previous studies. To determine the extent of government support in a bio cluster region, you can look at the organizational support at the central and local levels in that cluster.

The active business activities of the bio cluster are possible through the simultaneous start-up activities in the region and innovation activities of existing companies. In particular, the factors of start-up activity in the region can be seen as the starting point of a virtuous cycle that creates growth in the bio cluster. In order to identify the factors of the bio cluster's start-up activities by region, we can look at the number of small and medium-sized venture companies in bio industry established by region and the number of accelerators, one of the conditions for supporting start-ups.

The second criterion for determining how active a particular bio cluster is the innovation of companies in the cluster. Given that the bio industry has the characteristics of a science-based industry, bio companies' innovative activities are centered on research and development activities. In addition, in the bio industry, a network of cooperation among innovators in the ecosystem is very important in that industry members form a single ecosystem to create synergy through linkage and cooperation among members. In order to identify the factors of innovation activities by bio cluster region, we can look at research and development investments by bio-companies by region and the cooperative network of cluster members by region.

Table 4 shows the integrated framework for bio cluster management including the success factors and items in each success factor.

Table 4: Integrated Framework for Bio Cluster Management

\begin{tabular}{|c|l|}
\hline Success Factors & \multicolumn{1}{c|}{ Items for Management } \\
\hline Knowledge base and expertise & $\begin{array}{l}\text { - Number of Knowledge such as patent and paper } \\
\text { - Number of Excellent Workers in Bio Industry }\end{array}$ \\
\hline Industrial infrastructure & $\begin{array}{l}\text { - Sites, Facilities and Equipment } \\
\text { - R\&D Infra and Production Infra }\end{array}$ \\
\hline Funding and investment & $\begin{array}{l}\text { - Use of R\&D funds } \\
\text { - Venture Investment Conditions }\end{array}$ \\
\hline Government support & $\begin{array}{l}\text { - Support of central government for budget and organization } \\
\text { - The support of local government for budget and organization }\end{array}$ \\
\hline Start-up activities & $\begin{array}{l}\text { - Number of venture companies in bio industry } \\
\text { - Number of accelerators for venture companies }\end{array}$ \\
\hline \multirow{2}{*}{ Innovation activities } & $\begin{array}{l}\text { - R\&D investment by bio companies } \\
\text { - Cooperative network of cluster members }\end{array}$ \\
\hline
\end{tabular}




\section{Conclusion}

This study outlines the success factors of bio cluster in parallel with literature and case studies and presents a management framework for the success of bio cluster. This enabled us to identify the bio cluster success factors from a theoretical perspective and to present integrated success factor framework additionally.

The following conclusions and implications can be derived from this study. First, the success factors of bio cluster are well applied to most of the success stories, although there are differences in degree by type of bio cluster. Therefore, the integrated framework presented in this study could be used universally for various types of bio cluster. Second, this study confirmed again that systematic development and management of bio cluster requires a successbased approach. We identified the key success factors of the bio cluster and the main items to build those factors properly through the literature review and case study. In order for existing bio clusters in the country to develop to advanced levels, it will be necessary to identify which factors should be strengthened in terms of success factors of bio cluster. And by exploring and implementing specific measures to reinforce the deficient factors, we will be able to continuously monitor and manage the evolution of the bio cluster. Third, not only government-led bio cluster but also private-led bio cluster needs government support factors which are critical to the success of bio cluster. In particular, the government's continuous and systematic support is very important in that the market size of the bio industry of Korea is smaller than those of advanced countries and the market status of domestic bio companies are lower than those of global leading companies. Continuing government support will be even more important, given that the bio industry has a long time to take from research and development to commercialization due to its nature.

This study is highly useful in the field of management in that it not only comprehensively reviews the success factors of the bio cluster and presents them as a systematic framework, but also includes the performance measurement and monitoring items necessary for successful management of bio cluster. However, it will be necessary to identify the limitations of this study and look at future studies that can overcome it. First, the case studies in this study did not perform an in-depth analysis of new success factors, given that they focused on the success factors of the bio cluster presented by existing literature. Future studies will also need to analyze bio cluster cases around the world to discover new success factors. Second, the various bio cluster cases covered in this study did not analyze the differences in success factors. In the future, we will be able to see if there are differences in success factors for each type of bio cluster and whether there are differences in impact of each success factors even if they are the same success factors. Third, the framework for the integration success factors presented in this study provides representative items for evaluating and managing bio clusters, but may not yet contain sufficient items. Future studies will require a comprehensive review of management cases in academic research and business practice, and the development and utilization of improved integrated framework that can enhance completeness of current framework both theoretically and practically.

\section{References}

BIO (2000). Networks of innovation: Regions collaborating to compete in the global market, BIO 2000 Conference.

Bok, D. K., Kho, J. M., Sim, S. M., \& Kho, Y. S. (2002). The Development Strategy for Industry Cluster, Samsung Economic Research Institute.

Cho, H. S., Hwang, T. W., \& Lee, J. H. (2019). Bio-healthcare Industry, The Korean Journal of Bioeconomy, 2(2), 23-67.

Coe, N. M., Kelly, P. E., \& Yeung, H. W. C. (2007). Economic geography: A contemporary introduction, Oxford, UK: Blackwell Publishing.

Coenen, L., Moodysson, J., \& Asheim, B. (2004). Nodes, networks and proximities: On the knowledge dynamic of the medicon valley biotech cluster. European Planning Studies, 12(7), 1003-1018.

Department of Trade and Industry of U.K. (DTI) (1999). Biotechnology clusters, August.

Eun, E. K. (2015). Industry-academic cooperation in Cambridge bio cluster and its outcome. Korean Journal of Urban History, 13(1), 155-184.

Eun, E. K. (2016). A comparative study of growth strategies of bio cluster companies in San Francisco and Incheon. Journal of Industrial Economics and Business, 29(6), 2477-2497

Europe Innova. (2006). Do's and don'ts for biotech cluster development: The results of NetBioCluE.

Han, D. W. (2003). The policies of U.S. for biotechnology clusters. Healthcare Industry Technology Trends, Summer, 1, 158-165. 
Jeong J. S., Lee, S. H., Kim, H. S., \& Kim, E. Y. (2011). National innovation system of biotechnology in Korea: Measures for improving the competitiveness of clusters. The journal of professional management, 14(3), 25-63

Kang S. G., Lee, J. H., \& Lee, S. H. (2019). A Study of industrial linkage structure and economic impacts of R\&D investment in Korean bio industry: Compared with 2006 and 2013 using output-output Multiplier in RitzSpaulding Input-Output Mode, Journal of Industrial Economics and Business, 32(3), 1059-1090.

Ketels, C. B. (2003). The development of the cluster concept: Present experiences and further developments. Paper presented at the NRW Cluster Workshop in Duisburg, Germany.

KHIDI (Korea Health Industry Development Institute) (2012). The development plan for advanced medical complex. Research Report.

Kim, I. J. (2011). A Suggestion for the implementation of Korean-style biotechnology clusters. STEPI Research Report, 1-49.

Kim, T. W. (2014). A study on the characteristics of government-initiated biomedical clusters: focused on the cases of the countries of East Asia. The Korean Journal of Local Government Studies, 18(3), 279-311

Lee, Y. D., \& Kim, J. S. (2003). Study on the driving forces of biotechnology cluster in Daedeok valley. Journal of management \& economics, 26(1), 189-208.

Lee, J. H., \& Lee, C. W. (2008). Reconsidering the concept, typology and theories of agglomeration and cluster in economic geography. Journal of the Economic Geographical Society of Korea, 11(3), 302-318.

Lee, J. H., \& Lee, C. W. (2015). The Dynamic Evolution of the Cambridge Cluster and the Entrepreneurial University. Journal of The Korean Association of Regional Geographers, 21(3), 489-502.

Murray, F. (2004). The role of inventors in knowledge transfer: sharing in the laboratory life. Research Policy, 33.

OECD. (2001). Innovative clusters: Drivers of National Innovation System.

Park, M. S., \& Jeong, Y. J. (2019), The Effects of the Government Support Policy on Small and Medium-Sized Biotechnology Firms, The Korean Journal of Bioeconomy, 2(1), 93-124

Pisano, G. P. (2006). Science business: The promise, the reality and the future of biotech. MA: Harvard Business School Press.

Porter, M. E. (2000). Location, competition and economic development: local clusters in a global economy. Economic Development Quarterly, 14(1), 15-34.

Powell, W., Koput, K., Bowie, J., \& Smith-Doerr, L. (2002). The spatial clustering of science and capital: Accounting for biotech Firm-venture capital relationships. Regional Studies, 36(3), 291-305. 